\title{
Política e epistemologia no CBCE: resenha do livro Leituras da natureza científica do Colégio Brasileiro de Ciências do Esporte
}

Felipe Quintão de Almeida* Alexandre Fernandez Vaz**

\begin{abstract}
Resumo: Leituras da natureza científica do Colégio Brasileiro de Ciências do Esporte (CBCE), organizado por Amarílio Ferreira Neto (2005), procura apresentar uma síntese dos rumos político-científicos da principal entidade científica da Educação Física/Ciências do Esporte do Brasil nas últimas décadas do século XX. A pluralidade de posições, as divergências e as eventualmente críticas mútuas presentes em suas páginas indica a caminhada até o momento, bem como expressa desafios que precisam ser enfrentados pela área. Trata-se de um aberto convite aos pesquisadores do campo ao diálogo sobre os paradoxos políticos e epistemológicos que assolam toda e qualquer entidade científica em tempos incertos e ambíguos como o nosso.
\end{abstract}

Palavras-chave: Sociedades científicas. Conhecimento. Educação Física.

Não há dúvidas sobre a existência de relações entre ciência e política, duas expressões dos fazeres humanos que, embora cruzadas, guardam especificidades que não permitem que uma seja reduzida à outra. Nesse sentido, se não é possível sustentar que uma disciplina acadêmica se instale apenas em função de sua justificativa epistemológica ou política (BRACHT, 2000), o livro Leituras da natureza científica do Colégio Brasileiro de Ciências do Esporte, organizado por Amarílio Ferreira Neto em torno de seis textos e cinco autores, incluindo o próprio organizador, convida a pelo menos um desafio: compreender o papel histórico (portanto, político) assumido pelo

* Doutorando do Programa de Pós-Graduação em Educação da Universidade Federal de Santa Catarina (CED/UFSC). Membro do Laboratório de Estudos em Educação Física (LESEF/ CEFD/UFES) e do Núcleo de Estudos e Pesquisas Educação e Sociedade Contemporânea (CED/UFSC). E-mail: fqalmeida@hotmail.com

** Doutor pela Universidade Hannover; professor dos Programas de Pós-Graduação em Educação e Educação Física da Universidade Federal de Santa Catarina (UFSC); coordenador do Núcleo de Estudos e Pesquisas Educação e Sociedade Contemporânea; pesquisador CNPq. E-mail: alexfvaz@pq.cnpq.br

Movimento, Porto Alegre, v.13, n. 02, p.221-230, maio/agosto de 2007. 
Colégio Brasileiro de Ciências do Esporte (CBCE) nos contornos atualmente exigidos a uma sociedade científica. Cada autor que o compõe, a partir de diferentes concepções teóricas e políticas, emite suas posições com "pretensões de verdade sobre o que é e o que deve ser o CBCE", como destaca Molina Neto (2005, p. xii), no prefácio.

O texto de abertura, "Leituras dos 20 e 25 anos do CBCE: política, comunicação e (in)definição do campo", do próprio Ferreira Neto, dá o tom do intento do livro ao colocar em evidência problemas políticos, de comunicação e de (in)definição do campo científico por via do diálogo com interpretações sobre o desenvolvimento da Educação Física brasileira nas últimas três décadas. Para tanto, elenca como documentação-fonte o número especial da Revista Brasileira de Ciências do Esporte (RBCE), de 1998, comemorativo dos seus 20 anos, além de textos específicos, oriundos de mesas-redonda, dos anais do XIII Congresso Brasileiro de Ciências do Esporte (CONBRACE), de setembro de 2003, ano em que a instituição comemorava seu $25^{\circ}$ aniversário. Ao proceder dessa forma, entende criar as condições para que o diálogo com os autores possa ocorrer e, assim, expressar sua própria "pretensão de verdade" quanto à natureza do que considera ser o papel de uma entidade científica na atualidade.

Após apresentar o conteúdo geral dos textos que compõem a primeira das duas fontes, Ferreira Neto inicia seu diálogo introduzindo, quando considera necessário, os interlocutores do XIII CONBRACE. Argumenta que não há produção científica acumulada no CBCE que dê azo à tarefa revolucionária da instituição, conforme predica Taffarel, advertindo a comunidade que tal postura (política) apenas pode levar ao CBCE à beira da falésia, deslegitimando-o como sociedade que produz ciência e dificultando o diálogo entre os diferentes modos do fazer científico que habitam ou poderiam habitar a entidade.

Logo após, o autor se dirige a um trabalho de Rossana Valéria de Souza e Silva ("O CBCE e a produção do conhecimento em Educação Física”), cujo texto também compõe a coletânea, no qual esta retoma um tema já tratado em outras ocasiões: a cientificidade na Educação Física brasileira e a produção em programas de pósgraduação da área. Ela apresenta um histórico das conquistas,

Movimento, Porto Alegre, v.13, n. 02, p.221-230, maio/agosto de 2007. 
dificuldades e retrocessos que marcaram a consolidação do (in)feliz casamento da Educação Física com a ciência, bem como do importante papel desempenhado pelo CBCE no fomento dos programas de pós-graduação no país.

No que diz respeito à natureza científica do $\mathrm{CBCE}$, a autora entende que, apesar de este não ser uma instituição cuja finalidade seja produzir conhecimento, trata-se de importante espaço para sua difusão e crítica, sendo ainda o locus representativo da área para debater as questões atinentes à pós-graduação strictu sensu.

A crítica de Ferreira Neto a Silva não se dirige tanto às posições da autora em relação à temática $\mathrm{CBCE}$ /pós-graduação, mas atinge no cerne mesmo a leitura da natureza (científica) do trabalho realizado pela autora ao longo dos últimos 15 anos. Assim, pergunta pela viabilidade teórico-metodológica da matriz que vem sendo utilizada por ela, ressaltando, contrariamente, a importância dos estudos empírico-analíticos para a qualidade da pós-graduação em Educação Física no Brasil e exigindo o mesmo rigor e força de sua crítica - algo que a autora já reconhece - para os estudos elaborados no campo das Humanidades. Há que se notar ainda que a autora coloca no mesmo plano o que chama de pesquisas empíricoanalíticas e a orientação positivista, uma premissa que de antemão prejudica o quadro categorial no qual se movem seus argumentos.

Seguindo com sua estratégia de exposição, Ferreira Neto chega às posições de Go Tani, Elenor Kunz e Valter Bracht, reconhecendo a fundamental contribuição desses autores para a consolidação da Educação Física como campo científico. Nesse contexto, irá ressaltar os distintos modus operandi que compõem a área, sem deixar de destacar a existência, nefasta em seu entendimento, de um sistema de controle político no CBCE, sendo o resultado mais imediato dessa situação a ineficiência gestora da instituição e os danos causados à "[...] democracia do mérito científico que deve orientar as ações da direção nacional, secretarias estaduais e GTTs" (2005, p. 17). Por conta disso, irá questionar a legitimidade acadêmico-científica de determinados GTTs, bem como perguntar pela ausência de outros - inclusive com caráter disciplinar - que pudessem absorver trabalhos como os enraizados na biodinâmica do movimento

Movimento, Porto Alegre, v.13, n. 02, p.221-230, maio/agosto de 2007. 
humano, já há alguns anos consolidados no âmbito da pós-graduação strictu sensu na Educação Física brasileira.

E é exatamente com o tema da pós-graduação strictu sensu na sua relação com o CBCE que Ferreira Neto convida Hugo Lovisolo ao debate. Retomando uma discussão iniciada em outro fórum, Lovisolo, em "Sobre a Pós-graduação em Educação Física", avalia positivamente o esforço brasileiro empreendido no campo da pósgraduação nas últimas três décadas, mas identifica alguns efeitos indesejáveis decorrentes das diretrizes atualmente adotadas. Do esboço sobre a política de desenvolvimento científico no país - seus dados gerais e alguns efeitos imediatos - Lovisolo nos apresenta um panorama da pós-graduação em Educação Física no Brasil, analisando dados de matrícula, da relação docentes/discentes e da titulação. Compara também o programa strictu sensu da pós-graduação da Universidade Gama Filho e da Universidade de São Paulo com o intuito de corroborar sua tese dos efeitos indesejáveis que a política de avaliação da pós-graduação, no caso da Educação Física, estaria provocando. Neste particular, ao partir do princípio que a esta é uma área fortemente vinculada à intervenção, reafirma sua já conhecida tese de que "[...] a avaliação deveria ser realizada a partir de objetivos específicos das áreas e dos programas e não de normas postas como universais" (2005, p. 75).

A aposta de Lovisolo para a reversão desse quadro - e as conseqüências que dele originam - passa pelo enfrentamento da tarefa de ser criada uma associação de pós-graduação em Educação Física ou modificar o estatuto do CBCE para que a plenária da pósgraduação caiba em seu interior.

Da problemática exposta por Lovisolo, Ferreira Neto apresenta sua posição acerca da natureza científica do CBCE: a pós-graduação independeria da entidade, embora a recíproca não seja verdadeira. Diante disso, advoga um acordo entre os pares para que a pós-graduação torne-se a locomotiva da instituição até "[...] que se analise detidamente a viabilidade ou não de transformação do CBCE em associação nacional de pós-graduação da área" (2005, p. 21). Advogando a prevalência do científico em detrimento do político, o autor procura por aí encontrar uma alternativa que confira

Movimento, Porto Alegre, v.13, n. 02, p.221-230, maio/agosto de 2007. 
atualização aos critérios de comunicação e definição do campo científico da Educação Física nesses tempos de acirrada competição científico-tecnológica.

Colocando-se, em alguma medida, na contramão de alguns argumentos de Ferreira Neto, Marcus Aurélio Taborda de Oliveira, no texto "Sobre a experiência e a história: a busca pela consolidação acadêmica da Educação Física brasileira", problematiza a ânsia cientificista da Educação Física em sua busca por legitimação acadêmica.

Apresentando uma crítica contundente ao que se considera um ponto de inflexão importante na história recente da Educação Física brasileira - a propalada "crise da Educação Física" anunciada nos anos 1980 -, Taborda de Oliveira traz novamente à baila as disputas e lutas por hegemonia política e epistemológica travadas no âmbito acadêmico da Educação Física, interpretando que o CBCE, tal como o conhecemos hoje, é resultado desses confrontos. Segundo seu entendimento, nesse conflito de interesses, nem sempre alimentados por causas tão nobres quanto se gostaria, residem os rumos que uma área que busca e pretende consolidar sua legitimidade acadêmica. Alerta, no entanto, que fazer ciência é também fazer política e não sendo qualquer das duas atividades uma experiência extra-humana, é preciso considerar que são elas realizadas sem os purismos freqüentemente supostos.

Sua posição sobre essa disputa de poder e de "pretensão de verdade" no âmbito da Educação Física brasileira e no próprio CBCE reside em basicamente dois pontos, já devidamente trabalhados em sua importante tese de doutorado (TABORDA DE OLIVEIRA, 2003). No primeiro, reclama da ausência da consideração da experiência dos professores que "pisam o chão da escola", já que a busca da tão almejada legitimidade acadêmica tem sido construída na desqualificação do discurso e da prática daqueles outros envolvidos com a prática da Educação Física: os professores escolares. O segundo ponto se refere à ênfase numa retórica cientificista, de forte cunho ideológico, para buscar a consolidação acadêmica de uma prática que não é e nem pode ser científica, a Educação Física. Tal compulsão encobria a constatação de que a realidade não é

Movimento, Porto Alegre, v.13, n. 02, p.221-230, maio/agosto de 2007. 
tão somente possível de ser lida a partir do esquadrinhamento científico, bem como obnubila o fato de a ciência ser um lugar de disputa, conflito e poder, como, aliás, segundo reafirma, acontece no CBCE. Esse processo em grande medida se dá por um certo desprezo à pluralidade, uma "[...] deslegitimação de outras possibilidades. E assim a história se faz também aqui como campo de negociações, de tendências em disputa, de possibilidades" (2005, p. 39).

$\mathrm{O}$ que restaria à Educação Física e ao $\mathrm{CBCE}$ seria, então, procurar entender a lógica que move o argumento do outro, já que aquela é composta de uma plêiade de influências disciplinares. Entretanto, e é neste ponto que Taborda de Oliveira parece colocar-se especificamente na contramão de Ferreira Neto, já que para isso a Educação Física não precisaria ser "científica" ou lutar por graus cada vez mais altos de cientificidade, mas sim reconhecer que a experiência é veículo por excelência de construção de sentidos do mundo e, por que não, do próprio CBCE. Se admitirmos isso, continua o autor, talvez possamos inscrever em outras bases a relação entre Educação Física e ciência, “[...] lembrando que os esforços de consolidá-la como ciência são pouco mais do que meros artifícios de demarcação de territórios corporativos" (2005, p. 43). Taborda de Oliveira aproxima-se de certa forma de Lovisolo, para o qual, como foi dito, a intervenção - e, portanto, não a pesquisa - seria o delimitador principal da área.

Os outros dois textos que compõem o livro, ao enfatizar menos a relação potencialmente explosiva entre ciência e política (científica), tratam de questões atinentes à produção do conhecimento na área. Assim é que novamente Ferreira Neto, em "Atualidade da pesquisa histórica na Educação Física: congressos e campos científicos", segue com o objetivo de incorporar a experiência social dos pesquisadores, agora, em nome da melhoria da qualidade da pesquisa histórica na área. Desse modo, seria profícuo saber "[...] o que se ganha e o que se perde ao dar ênfase a uma vertente dispensando outras contribuições do fazer da história e da historiografia." (2005, p. 129). Para tanto, dessa vez apresenta algumas notas sobre as práticas de produção da história e historiografia da Educação Física veiculada nos Congressos de História da Educação Física, Esporte,

Movimento, Porto Alegre, v.13, n. 02, p.221-230, maio/agosto de 2007. 
Lazer e Dança, e a produção do GTT Memória, Cultura e Corpo, hoje desmembrado em outros dois GTTs no CBCE.

Após criteriosa análise do material produzido, que não se nos permite aqui explanar, continua a defender a tese de alguns problemas de comunicação científica no interior da área que podem ser assim sumariados: 1) apesar do grande avanço qualitativo e quantitativo da pesquisa histórica em Educação Física, lazer, esporte e dança, bem como na dinâmica da formação de novos quadros envolvidos com estas temáticas, observa-se que no conjunto dos eventos há paradoxos nas "artes de fazer" dos seus chanceladores/ organizadores; 2) esses paradoxos, também presentes nas análises do material do GTT acima referido, supõem uma (in)definição do campo científico dessa subárea. Apesar desse quadro, acredita que nas duas esferas de análise "[...] há quadros de profissionais com autoridade científica reconhecida o suficiente para enfrentar essa empreitada" (2005, p. 154).

Antes de finalizar a resenha, nos encontramos com o texto de Terezinha Petrucia da Nóbrega, "Desafios da ciência, reflexão epistemológica e implicações para a Educação Física e Ciências do Esporte", cujo propósito é a reflexão sobre a prática científica na Educação Física, esperando, com isso, fomentar a discussão sobre alguns dos desafios epistemológicos do mundo contemporâneo e destacar suas implicações na área e no próprio CBCE.

Valendo-se de um expressivo ecletismo na fundamentação de suas proposições e partindo da compreensão de que a revisão epistemológica da área passa pela consideração de sua história, suas aspirações de cientificidade, objetos e métodos, a autora procura apresentar-nos uma espécie de "estado da arte" das principais temáticas epistemológicas que ocuparam a Educação Física desde meados da década de 1990, pleiteando, por intermédio do diálogo e do exercício da reflexividade, uma relação mais solidária entre os saberes e os membros que compõem a comunidade científica e profissional da área e do CBCE.

Segundo a leitura que faz da natureza científica do CBCE, sua configuração e consolidação como sociedade científica ocorre no

Movimento, Porto Alegre, v.13, n. 02, p.221-230, maio/agosto de 2007. 
esforço concreto de produção do conhecimento e da possibilidade de debater criticamente com os pares a qualidade desta. Sua perspectiva epistemológica indica como tarefa para o CBCE a necessidade de considerar a ciência que tem se realizado sob o "signo do acontecimento" (2005, p. 118), forma do operar que enfatiza a necessidade de as sociedades científicas preservarem a singularidade dos saberes e dos diferentes contextos e construírem pontes entre os distintos modos de compreensão da realidade. Tal postura possibilitaria novas linhas de fuga, mapas cognitivos para o conhecimento e conexões rizomáticas, além de múltiplas entradas para os encaminhamentos do CBCE como sociedade científica nas suas atividades de fomento, divulgação e crítica do conhecimento.

Considerar "Leituras da natureza científica do Colégio Brasileiro de Ciências do Esporte" é tarefa obrigatória para aqueles que, à sua maneira, estão vinculados à principal entidade científica da área da Educação Física/Ciências do Esporte. Se houver discordância em relação às teses nele contidas - e haverá, uma vez que elas não são coincidentes entre os autores -, não se pode ignorá-las. A pluralidade de posições dos autores acerca do papel político e científico do CBCE expressa um pouco do que é uma área que, com muita dificuldade, vem tentando se aperfeiçoar em meio aos paradoxos e ambigüidades que contornam uma sociedade científica. Diante das insondáveis incertezas que assolam essas entidades hoje, um fato, porém, nos parece incontestável: se os "surdos" sabem se comunicar e os "críticos de arte" são necessários no CBCE, em tempos difíceis como estes, "críticos da ciência" ainda têm seu lugar garantido - só com eles a fé inquebrantável no progresso científico pode ceder lugar à constatação de que o próprio esclarecimento reverte em mitologia, seu outro ex-negativo. Eis que sua dialética se confirma. Boa leitura!

Movimento, Porto Alegre, v.13, n. 02, p.221-230, maio/agosto de 2007. 
Readings on Scientific Nature of Brazilian College of Sport Science

Abstract: Readings on Scientific Nature of the Brazilian College of Sport Science, edited by Amarílio Ferreira Neto (2005), presents a synthesis of the politician and scientific routes from the main scientific association of Physical Education/Sport Sciences in Brazil in the last decades of 20th century. The plurality of positions, divergences and mutual critics that also appear in the book show its development until now and expresses the challenges to face. Its articles demand the dialogue about politicians and epistemological paradoxes of all scientific associations in our uncertain and ambiguous days.

Keywords: Societies, Scientific. Knowledge. Physical Education.

Lecturas de la naturaleza científica del Colegio
Brasileño de Ciencias del Deporte
Resumen: Lecturas de la naturaleza científica del
Colegio Brasileño de Ciencias del Deporte, organi-
zado por Amarílio Ferreira Neto (2005), intenta
presentar una sintiese de los rumbos político-cientí-
ficos de la principal entidad científica de la Educación
Física/Ciencias del Deporte de Brasil en las últimas
decadas del siglo XX. La pluralidad de posiciones,
las divergencias y las mutuas críticas que también
aparecen, presentes en sus paginas, indica el
precurso hasta el momento, así como es expresión
de los desafíos con los cuales se confronta el
área. Tratase de una amplia invitación a los inves-
tigadores del campo para que se ocupen del dialo-
go sobre los paradojos politicos y epistemológicos
que acometen toda y cualquiera entidad científica
en tiempos de incertidumbre y ambigüedad como
lo nuestro.
Palabras clave: Sociedades cientificas.
Conocimiento. Educación Física.

Movimento, Porto Alegre, v.13, n. 02, p.221-230, maio/agosto de 2007. 


\section{REFERÊNCIAS}

BRACHT, V. Educação Física e ciência: cenas de um casamento (in)feliz. Revista Brasileira de Ciências do Esporte, Campinas, v. 22, n. 1, p. 53-63, 2000.

FERREIRA NETO, A. (org.). Leituras da natureza científica do Colégio Brasileiro de Ciências do Esporte. Campinas: Autores Associados, 2005.

TABORDA DE OLIVEIRA, M. A. Educação Física escolar e ditadura militar no Brasil: entre a adesão e a resistência. Bragança Paulista: Editora da Universidade São Francisco, 2003.

Recebido em: 09/11/2006

Aprovado em: 20/03/2007

Movimento, Porto Alegre, v.13, n. 02, p.221-230, maio/agosto de 2007. 